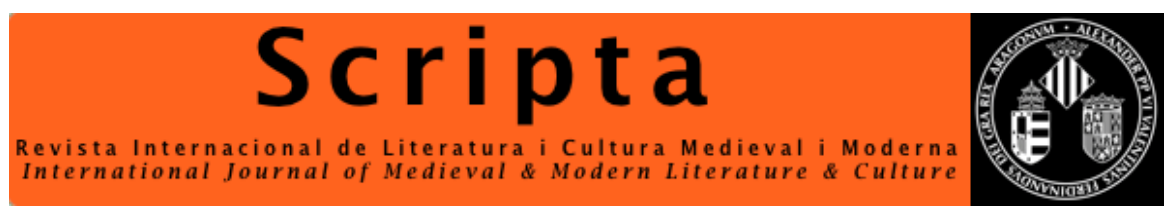

\title{
«Al aire» del to barroc
}

\author{
«Al aire» of the baroque tono
}

\author{
Lola JosA \\ lolajosa@gmail.com \\ Universitat de Barcelona
}

\begin{abstract}
Resum: El paisatge bucòlic es va convertir en una espècie de partitura i de joc metalíric en els tons barrocs de tal manera que sembla com si els intèrprets $i$ les veus que els canten només tinguessin que seguir les indicacions que els tòpics poètics dicten des del text per a que la sonoritat, l'harmonia i la música fossin possibles. Resulta molt curiós també que, tan tardanament, fos a propòsit de l'amor bucolicopastoral el pretext amb què l'incipient art del to es mostrés més experimental. Només aquest motiu musical podria justificar, que, a principis del segle XVII, proliferessin les composicions de tons de temàtica bucòlica i d'aquells altres que estan centrats en una Natura, si bé no idealitzada, no advertida pel més tardà panteisme egocèntric. En aquest treball ens centrarem, per tant, en les causes d'aquest esforç d'originalitat musical i de llurs èxits, així com la repercussió que va tenir en la poesia musicada. També seguirem l'evolució poeticomusical del to bucolicopastoral de la mà dels millors compositors peninsulars (alguns encara desconeguts) per a terminar oferint les característiques més significatives que permeten fixar-lo com una de les importants tipologies de la història de la música peninsular del segle XVII..
\end{abstract}

Paraules clau: to barroc, poesia i música del segle XVII, bucolisme líric, estudi interdisciplinar, llenguatge poeticomusical.

\begin{abstract}
The bucolic landscape became a kind of sheet music and metalyrical game in baroque tonos in such a way that it seems as if the performers and the voices that sing them have only to follow the indications that the poetic topics dictate from the text so that the sonority, harmony and music were possible. It is very curious also that, so belatedly, it was on the subject of pastoral-bucolic love the pretext with which the incipient art of the tono was more experimental. Only this musical motif could justify, that, at the beginning of the XVII century, the compositions of bucolic tonos proliferated and of those others that are centered in a Nature, although not idealized, not noticed by the later egocentric pantheism. In this work we will focus, therefore, on the causes of this effort of musical originality and its achievements, as well as the repercussion that it had on musicalized poetry. We will also follow the poetic-musical evolution of the bucolic-pastoral tono along with the best peninsular composers (some still unknown) to end up offering the most significant characteristics that allow us to fix it as one of the important typologies of the history of the peninsular music of the XVII century.
\end{abstract}

Keywords: Baroque tono; Poetry and music of the seventeenth century; Lyric bucolicism; Interdisciplinary study; Poetic-musical language. 
La poesia musicada (romanços amb o sense tornada, cobles, seguidilles, dècimes...) matisà les necessitats líriques del segle XVII com no ho va fer cap altre art. Per aquest motiu, el to barroc va resultar un art complex. No obstant això, malgrat les dificultats que comporta buscar, transcriure, editar, gravar i recuperar aquella sonoritat poètic-musical, la labor interdisciplinària entre musicologia i filologia ens ha descobert una veu i una música integrades amb plena consciència artística i magisteri (Josa \& Lambea, 2000, 2002, 2003, 2005 i 2007), arribant, fins i tot, a enriquir i a transformar la que ja era per si mateixa una revolucionària preceptiva dramàtica com va ser la Comedia Nueva. El to assolia una profunditat teatral sense precedents per crear arguments musicals paral lels al desenvolupament de l'acció, perquè cada cançó, ballada o no, tenia la seva pròpia funció relacionada amb la trama, aconseguint, d'aquesta manera, una difícil perfecció que, en realitat, complia amb una veritable inquietud nascuda en l'Europa d'aquell període i que anava a caracteritzar el naixement de l'Edat Moderna: la individualització del temps (Andrés \& Josa 2019, e. p.; Maravall 1982: 368-369; i Deleuze 1989) La música i el teatre, en qualitat d'arts sustentades sobre el temps, estaven obligades al segle XVII a apurar, amb tots els ressorts expressius, el nou concepte temporal que, des de finals del XVI, va deixar de ser mera orientació per erigir-se en experiència individual i en dramàtica dialèctica amb un temps comú $i$ universal (Andrés \& Josa 2019). Només aquest temps íntim va ser el que, a partir de llavors, va oferir a l'home la seva pròpia durada i l'explicació del món. La correlació i el flux objectiu sostenien i refermaven una nova consciència del present on es va forjar el Barroc, «l'art informal per excel lència» perquè va proposar la forma, l'expressió, plegada com a manera que només existeix en la ment (Deleuze 1989: 51). Res, doncs, estava buit; plecs del cant, d'allò més íntim de l'home en la clausura de l'ànima, i replegaments de la partitura, del text, de la posada en escena sota la condició de la exterioritat. Però, com sempre, hem de fer-nos preguntes: per què el to barroc va ser tan decisiu en la cultura del XVII?; d'on venia la seva inspiració, la seva més recòndita obstinació per ser-ho?

Amb la música (art del temps per excel lència) es va voler apurar l'expressió de tot això perquè cantar anava a convertir-se en sinònim d'unir (Andrés 2017: 36); el segle XVII ho necessitava en la seva operació infinita, en els seus buits aparents, en el seu saber recórrer a la il lusió, a la imaginació per crear allò que ja existia existent i reconvertir en presència el no-res vist. Tota música vocal de l'època barroca està regida per la màxima expressiva de descriure, emfatitzar o ressaltar els afectes, sentiments o situacions de tot tipus continguts en els textos poètics: emocions, descripció de fenòmens o d'accidents naturals... Això explicaria que el panteisme egocèntric dels poetes barrocs no restava lluny del que fos característic del Romanticisme, ja que la sentimentalizació de la Natura va permetre establir comparacions entre el malestar de l'home i els elements i les forces deslligades. Colodrero de Villalobos iguala la seva tristesa a la d'un dia tempestuós i Bocángel, passejant pel camp, diu «aplicar a la seva cura» quant li envolta. El pastor Riselo de Liñán de Riaza tem l'amenaça del cel, i pensa que perdrà el seu ramat sota la tempesta: passats els ennuvolats arriba l'equilibri, la

1 «Canción métrica para la música compuesta de varias coplas» (Dic. Aut.) 
placidesa de nou, com si la Tempestat de Giorgione s'hi hagués esfumat llenç a dalt. I enmig de tant desconcert i adversitat climàtica, de tant vent i pluja i rius desbordats, que arrosseguen barraques, gossos i bestiars, Luis de Góngora diu no témer més que les seves penes (Andrés \& Josa 2019). Com no anava a tenir la preceptiva musical de l'època l'obligada norma de recordar-li o indicar-li al compositor el principi de donar sonoritat als afectes continguts en els versos? Pedro Cerone va escriure en el seu Melopeo la següent indicació sobre la manera concreta que el compositor hauria d'abordar una obra musical. Li exigia les següents condicions:

\footnotetext{
Buena composición, buen aire, solfa graciosa, diversidad de pasos [intervals musicals], imitación bien puesta, que cada voz cante con donaire usando pasos sabrosos. Y la parte más esencial es hacer lo que la letra pide; es, a saber, alegre o triste; grave o ligera; lejos o cerca; humilde o levantada; de modo que haga el efeto que la letra pretende para levantar a consideración los ánimos de los que están oyendo (Cerone 1969, II: 695).
}

Tot el corpus de tons del segle XVII es regeix pel conjunt d'aquestes regles. Després de la paraula «silenci», per exemple, els compositors acostumen a introduir unes pauses o silencis musicals que emfatitzen la quietud i la introspecció. També la paraula «sospirs» obliga a interrompre el discurs musical mitjançant breus pauses que separen les síl labes, interrompent la melodia en la paraula, alguna cosa que no contemplava la teoria musical de l'època, a excepció de fer-ho amb els «sospirs». Diu Cerone:

\begin{abstract}
Como hecho tiene Pedro Luis de Prenestina en aquel madrigal a 4 voces de su prim[er] lib[ro] que comienza Queste saranno ben lagrime; en la palabra sospiri, a la cual divide en dos partes con pausa menor, haciendo que todas cuatro voces canten sospi, $r i$; y esto así hizo para imitar más el efecto natural del sospiro. [...] O como hizo Juan Nariz, en el madrigal a 5 voces que comienza Cualquiera pecho duro, en el verso Cortó mis tristes y ásperos sospiros, adonde, para imitar el sentido de la letra en todas las partes, a la palabra Cortó, va cortando con un sospiro; y lo mesmo hace a la palabra sospiros, cantando en esta manera: Cor, tó mis tristes y ásperos sos, pi, ros. En estas y semejantes ocasiones, pues, por la imitación de la letra, se puede dividir la palabra, mas, en otra manera, nunca será permitido (Cerone 1969, I: 304-305).
\end{abstract}

El pas del Renaixement al Barroc com millor podem entendre-ho és com a transformació del cosmos en mundus. No oblidem que el desenvolupament de la música renaixentista:
no puede concebirse sin la filosofía que generó una idea, hasta entonces un tanto difusa y en cuya cristalización se implicaron pensadores como Ficino, Piccolomini, Pico della Mirandola y Pomponazzi, pero también, fuera de Italia, Erasmo y Vives, y años después Montaigne, entre muchos otros: esta idea no es otra que la conformación del individuo moderno concebido ya como finalidad, como un cometido, ya dueño de su devenir (Andrés 2017: 71).

Contràriament al que succeïa durant l'Edat Mitjana, quan aquesta destinació pertanyia completament a l'ordre diví. Aquesta forma individualista i subjectiva de pensar l'existència va ser, i de manera 
gens lenta, desvinculant-se d'un món entès com a abstracció per convertir-se, per dir-ho en termes musicals, en la concreció d'una melodia de dibuix molt definit. Una melodia capaç de narrar i descriure la nova visió del compositor, però també de l'oïdor. La modernitat no és una altra cosa que el naixement d'aquest centre anomenat individu, és a dir, allò que no es divideix, perquè ja se sent constituit, que és tant com dir culminat. La Història moderna té inici quan vam començar a preguntar-nos pel nostre sentit al món i l'esdevenir en ell.

La literatura, l'art, la música revelen aquesta necessitat de recollir-se i pensar, pensar en el veritable conflicte de qui desperta a una nova consciència marcada per la subjectivitat. Per això podem reconèixer en la música de finals del Renaixement i principis del Barroc un procés, de vegades radical, d'introspecció, de reflexió sobre un mateix. I arribat ja el Barroc es defineixi com el període de la melodia o monodia acompanyada. Aquest pas el veiem de manera molt clara en els madrigalistes italians de l'últim terç del segle XVI, cada vegada més inclinats a subratllar la melodia superior i supeditar a ella la resta de les veus. L'objectiu d'aquesta voluntat monòdica es va produir, sobretot, en la música vocal, que exigia, cada vegada més, la comprensió del poema. La lletra no podia seguir estant tan supeditada a l'estructura musical, ara es feia necessari expressar el pensament del poeta, el seu afecte, la seva passió. La paraula música començava a tenir una connotació d'intimitat (Andrés 2017: 73).

Sorprèn el desig d'aquells músics i poetes per convertir-ho tot en sonoritat. Al seu moment Virgili va sentir aquesta mateixa necessitat de cobrir amb la beatitud de les Bucòliques la desolació causada per les imatges d'una realitat contrària, el qual l'esquena ensangonada i fumera del rerefons era el d'una guerra civil desfermada a la mort de César. D'aquí els pastors coronats de flors, d'aquí l'argentada olivera, la zampoña regalada per Dametas i el tou salze. Benvinguts la nuesa de Venus i les fonts d'aigües musicals. El paisatge bucòlic va arribar a la cançó barroca amb la llicència virgiliana i dels mestres italians, i amb la permeabilitat suficient per donar expressió als nous matisos de la manera d'estar i d'entendre el món al segle XVII. El bucolisme es va convertir en una sort de partitura i de joc metalíric en els tonos barrocs de tal manera que sembla com si els intèrprets i les veus que els canten només haguessin de seguir les indicacions que els tòpics poètics dicten des del text perquè la sonoritat, l'harmonia i la musicalitat fossin possibles. Així mateix, resulta molt curiós que, tan tardanament, fora a propòsit de l'amor bucòlic-pastoril amb el qual l'incipient art musical del to experimentés més. Només aquest motiu musical podria justificar que, a principis del segle XVII, proliferessin les composicions de tons de temàtica bucòlica i d'aquells altres que estan centrats en la Naturalesa, perquè en ella la veu lírica troba, ja no un mut testimoni de les cures, sinó un mirall dels mateixos, motiu pel qual els elements comuns i tipificats del paisatge bucòlic queden transformats per un nou sentir i pensar el sofriment (Josa \& Lambea 2007 i 2012).

Pensem que la tristor del XVII neix, en part, de la certesa que no hi havia més base que el moviment. Per això mateix, pocs elements com l'aigua van tenir per als poetes barrocs tan alta capacitat simbòlica, perquè, entre altres coses, representa la qualitat del transparent, és a dir, del fràgil: és 
cristall, cos eteri. No pesa, es trenca fàcilment, com la vida. La contemplació de la tranquil la superfície d'un llac fa reflexionar a Saavedra Fajardo, doncs en tirar una pedra a l'aigua:

\begin{abstract}
se van encrespando y multiplicando las olas, nacidas unas de otras, que cuando llegan a la orilla son casi infinitas, turbando el cristal de aquel liso y apacible espejo, donde las especies de las cosas, que antes se representaban perfectamente, se mezclan y confunden. Lo mismo sucede en el ánimo, después de cometido el error (Empresas políticas, LXV).
\end{abstract}

L'aigua, a més, és el que escapa irreparablemente $\mathrm{i}$ «alimenta todos los símbolos de la fluidez, inconstancia y plasticidad móvil» (Rousset 1972: 212). Una altra cosa va importar als poetes: l'aigua oferia una capacitat de metamorfosi molt superior a la de qualsevol altre element. En cascades, fonts, sortidors i rius es reflectia el canviant món, irrevocable d'altra banda, ja que l'aigua, com el temps, no pot tornar enrere, corrent amunt. Una font serveix a Manuel de Salinas per meditar sobre la durada de la vida humana. Les fonts i els rierols imiten en els jardins la mutació de la Naturalesa i, com la destinació de l'home, arriben al mar per perdre's en allò inabastable. L'aigua, sempre fugitiva, fa del món un teatre hidràulic en el qual els actors són els déus i els rius, però sobretot els cursos d'aigua que acaben despenyant-se: unides la caiguda i l'aigua, dos arguments per a la simbologia del segle XVII. Recordant la tràgica fi d'un rierol, Castro i Anaya ho descriu com un Ícar caigut, i en un altre to trobem que la font no arriba plàcida al mar, sinó que es desploma.

Però l'aigua també és un element de salvació. És veritat que en la seva fluïdesa no pot tornar al seu origen, però sí pot detenir-se en el seu propi cabal; el gelat torrent i els cristalls de la font esdevenen eterns. Per primera vegada no hi ha mort en allò transitori; potser sigui una forma de repòs en el no-res. Mentre el gel dura, el flux es deté. Salcedo Coronel parla d'un rierol que està en presons de gel detingut, i Esteban Manuel de Villegas escriu: «Para, blanco riachuelo, / hecho cinta de hielo». Però, tot és llei de la Naturalesa:

\footnotetext{
la hermosura provechosa de los montes, firmes costillas del cuerpo muelle de la tierra, aumentando su hermosa variedad: en ellos se recogen los tesoros de las nieves, se forjan los metales, se detienen las nubes, se originan las fuentes (Gracián, El Criticón, I, Crisi tercera).
}

Tot està format per contraris, i així el sol vindrà a deslligar la plata i a posar una altra vegada el món en moviment: la roda temporal gira novament per al drama, perquè la successió, igual que la calor, són principis de vida, i la vida, un camí cap a la mort.

Un exemple d'aquesta realitat canviant està protagonitzat pel riu: el seu curs convida a l'evocació, és un gran mirall mòbil que reflecteix el rostre de qui s'acosta a la riba confessionalment i observa els seus trets envellits per l'efecte de la mobilitat del corrent. El riu és germà de l'experiència i el seu córrer cap al buit accepta la transcripció que tot ésser humà fa de si mateix. Ja que està solament en la Naturalesa, s'identifica amb una altra solitud que va a perdre's en la immensitat. Plora la seva destinació, i amb això augmenta el cabal de les aigües, hipèrbole que tant va agradar 
als poetes barrocs i que no deixa d'evidenciar la intenció de sumar-se a qui escapa. Francisco de Francia y Acosta confessa al Duero la seva desgràcia amorosa, i el comte de Salinas refereix que, si la seva existència es reflecteix en els estels errants, en plorar s'uneix al que flueix terrenalment (Andrés \& Josa 2019). Els músics van saber composar la sonoritat de totes aquestes circumstàncies i característiques líriques. Un bon exemple ho trobem en Juan Hidalgo i el to «El curso transparente», amb versos d'Agustín de Salazar y Torres $^{2}$ que pertanyen al primer acte de la seva comèdia Los juegos olimpicos:

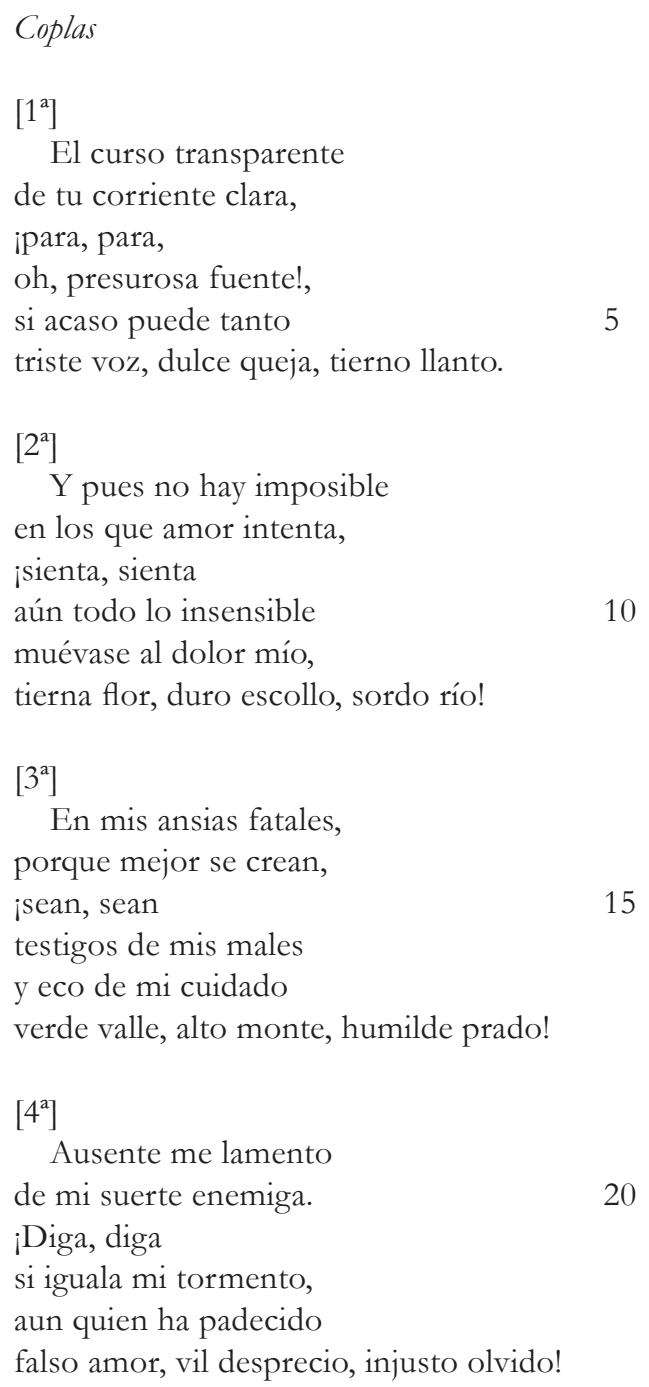

2 Vid. Josa \& Lambea 2017: 40-47 (text) i 161-164 (música). 
$\left[5^{a}\right]$

Aun el bruto más fiero

25

ausente mueve a llanto.

¡Tanto, tanto

puede el dolor severo

que gimen en su esfera

mudo pez, ave dulce, ruda fiera!

30

$\left[6^{a}\right]$

¡Ay, Paris fementido,

si mis ansias supieras,

vieras, vieras,

a pesar de tu olvido,

que con la pena mía

muere el sol, nace el alba, vive el día!

[Estribillo]

Peces, fieras, aves,

isentid mis males!

Plantas, flores, peñas,

illorad mis quejas!

Montes, valles, ríos,

¡oíd mis suspiros!

¡Oíd, sentid, llorad,

pues Amor reina

en riscos y flores,

en plantas y peñas,

en montes y ríos,

en aves y fieras!

El repertori de to humà és, en un altíssim percentatge, joc metalíric, pretext per justificar la paraula en si; el cant mateix. I els llocs comuns d'allò bucòlic ho permeten com cap altre tòpic, ja que brinda una naturalesa sonora, musical (els airecillos, les aigües que flueixen cristal lines, els ocells que canten, etc.), i perquè aquesta plàcida i sonora naturalesa era inspiració i marc d'escenes que combinen la tranquil litat amb la malenconia, com succeeix en ElQuijote, en les obres de Juan de la Cueva, Tirso de Molina i Vicente Espinel, per esmentar alguns.

La fina sensibilitat barroca va percebre l'abisme que hi ha entre la veritat i la versemblança, i ho va convertir en principi creatiu que va exigir que una obra es justifiqués per si mateixa $i$ en funció d'unes lleis capaces d'aconseguir la il lusòria autonomia de l'art i de la seva lúdica autorecreació. Aquest va ser l'assoliment de la novel la i del teatre del XVII, i, per descomptat, del llenguatge poètic-musical, del to humà. La música, art del moviment-d'aquesta preocupació constant al segle XVII-, tenia totes les possibilitats per realitzar amb exactitud allò que la paraula poètica a l'humà sospirava per dir, doncs la inaccessibilitat amorosa coincidia amb la inefabilitat poètica (Josa \& Lambea 2013: 42-44). Per aquest motiu el cant va ser el perfecte 
pretext per justificar la paraula i la música acordada. Però no oblidem, tampoc, que el segle XVII es va fonamentar en la màxima que l'art de la paraula oportuna va parell a l'art de l'oportú silenci (Egido 1996: 17-47 i 48-65). Sabent això, en els tons humans el verb es realitza mitjançant el cant, i al discurs verbal se li suma el musical amb el seu propi significat limítrof i el seu silenci in extremis que és amb el qual es mesura la perfecta harmonia una vegada conclosa, ja que, en la cultura aurisecular, els límits són l'eix de les relacions que mantenen allò tangible amb allò intangible i, en conseqüència, el silenci havia de ser tractat com la veritable fi de la paraula (Steiner 1990 i Rodríguez de la Flor 1997). Això va suposar un dels fonaments més importants de la singular dialèctica barroca assentada en un significant clarobscur del que es va nodrir tota aposta estètica i tota formació conceptual discursiva (Gállego 1966). Recordem que un dels temes barrocs predilectes va ser el d'uns pastors meditant al costat d'una sepultura envoltada del tranquil paisatge bucòlic, volent expressar amb això que una existència feliç també sucumbeix a la mort, i que la pròpia Arcàdia serveix de reflexió sobre el pas del temps i la finitud.

La conjunció entre música i poesia generava, en conseqüència, la importància dels seus contraris: la del cant, o bé, la necessitat del silenci. Per aquest motiu trobem tants elements retòrics que fan explícita aquesta interrelació de contrastos que permeten l'execució de gran part dels tons barrocs: igual que una imatge s'ofereix a la vista aillada d'un contínuum espaitemporal, -cobrant significació dins d'uns límits que subratllen el buit que hi ha després d'ells, i, en conseqüència, el no-res que precedeix i segueix a la imatge-, així la paraula en ser pronunciada respecte al silenci. I si el verb es realitza mitjançant el cant, al discurs verbal se li suma el musical amb el seu propi significat limítrof i el seu silenci in extremis que és amb el qual es mesura la perfecta harmonia una vegada conclosa (Josa \& Lambea 2013: 43a).

Sis exemples paradigmàtics els trobem al preciós cançoner conservat a Lisboa: «Dormido yace el amor», possiblement del compositor Jerónimo Latorre; «No confeséis, corazón»; «Ave sonora del aire»; "Corazón, ¿para qué buscas...?»; "Quién me dijera en otro tiempo», i «Soledades importunas» (Josa \& Lambea 2011: 42, 56, 67, 70, 76 i 83). En tots ells, o la tirania del petit déu Amor, o la inaccessibilitat de l'estimada, o la paradoxal naturalesa de tot amant, la falta d'interlocutor o les malenconioses i gongorines solituds són els motius poètics que obren la dialèctica entre la necessitat de cantar i el prudent que seria callar per no despertar al déu tirà, per no donar-li esperons al dolor i la tristesa, o per permetre a la retòrica del silenci que demostri la seva eloqüència davant les imposicions de les antigues leys d'amors. Sabem que Petrarca va ensenyar a cantar la naturalesa paradoxal de l'amor humà i cap període com el barroc va saber extremar totes les conseqüències que d'això es deriven, perquè, en consolidar tots els paràmetres del petrarquisme, l'imperi de la solitud i del silenci, la retòrica de les llàgrimes i dels impulsos del cant es van convertir en un univers expressiu moltíssim més ampli per la extremositat d'allò paradoxal que la força incontenible de la paraula poètica va establir. Així mateix, des del llenguatge, la raó i la paraula es pretenia alterar la realitat fins al punt d'elevar tota impossibilitat humana en l'amor als cims d'una 
eròtica lingüística (Sarduy 1969: 57), a la que sumar-li eròtiques plàstiques i musicals; pluralitat de perspectives en les superposició de tòpics i llenguatges artístics.

Una de les lliçons apreses del Renaixement era que la necessitat del cantar o del callar es mesurava, també, molt millor des del diàleg. Per això el recurs dialogístic està tan present, vertebrant l'estructura de gairebé la totalitat dels tons, condicionant la disposició de les dues unitats líriques, o, així mateix, permetent veus narratives, tan característiques dels romanços, que matisin el concurs de les diferents veus. Aquí estan els tons del dolor i els laments amorosos, els bucòlicpastorils o els diàlegs amb una Naturalesa viva que sap expressar-se amb sons més eloqüents que les paraules i que està habitada per éssers que són transsumpte de l'humà. Excepcional testimoniatge d'això és el to «jOh, qué triste se lamenta...!» (Josa \& Lambea 2011: 75-76), en el qual la vida s'equipara al cant i la mort, al silenci. La retòrica de les exclamacions lastimosas de la veu que descriu i canta, se sobreposa al silenci del cant del cigne, però sense ella, tampoc la mort ens podria ser sentida. Cant-vida i silenci-mort, per tant, de la paraula i de la música com a metàfora dels seus creadors (Azara 1995).

A principis del segle XVII encara no han arribat els posteriors vols d'İcars i Faetonts que, en la poesia més tardana, vindran a remarcar els límits de la inefabilitat poètica i les vanes pretensions de l'amor desenganyat. En canvi, música i poesia les trobem ja agermanades per conjuminar contrastos i, a través de tímids artificis expressius, representar la dificultat de la gosadia d'amor i els seus riscos. És molt curiós que sigui a propòsit del aire de l'amor bucòlic amb què s'experimenti més. Potser l'empremta de la contenció i la dolcezza de l'estil de l'últim renaixement van ser la causa o, qui sap, la certesa dels poetes i compositors que amb la veu es pot restituir el que ja havia fugit per sempre més. 


\section{Bibliografia}

Andrés, R. \& Josa, L. (2019, en premsa) Tiempo y caída. La poesía barrocay sus abismos, Barcelona, Acantilado.

- (2016) El mundo en el oído: el nacimiento de la música en la cultura, Barcelona, Acantilado.

-. (2017) Claudio Monteverdi. Lamento della ninfa, Barcelona, Acantilado.

Azara, P. (1995) La imagen y el olvido. El arte como engaño en la filosofía de Platón, Madrid, Ediciones Siruela.

Bonnefoy, Y. (1970) Rome, 1630: l'horizon du premier baroque, Paris, Editions Flammarion.

Cerone, P. (1969) El melopeo y maestro. Tractado de música theórica y pratica, Bologna, Forni editore.

Deleuze, G. (1989) El pliegue: Leibnizy el barroco, Barcelona, Paidós.

Díaz Marroquín, L. (2008) La retórica de los afectos, Kassel, Reichenberger.

Egido, A. (1996) La rosa del silencio. Estudios sobre Gracián, Madrid, Alianza Editorial.

Flórez Asensio, M. A. (2006) «Los vientos se paran oyendo su voz. De "partes de música" a "damas de lo cantado": sobre la evolución de la técnica vocal en el teatro español de los siglos XVII y XVIII», Revista de Musicología, 29/2, pp. 521-536.

Fubini, E. (2005) La estética musical desde la Antigüedad hasta el siglo XX, Madrid, Alianza Editorial.

Gállego, J. (1966) Visión y símbolos de la pintura en el Siglo de Oro, Madrid, Aguilar.

JosA, Josa, L. \& Lambea, M. (2000/2003/2005) La música y la poesía en cancioneros polifónicos del siglo XVII. Libro de Tonos Humanos (1655-1656), 3 vols., Barcelona, CSIC.

- (2003b) «Las trazas poético-musicales en el romancero lírico español», Edad de Oro, 22, pp. $29-78$.

(2004/2006/2011) La música y la poesía en cancioneros polifónicos del siglo XVII: cancionero poéticomusical hispánico de Lisboa, 3 vols., Madrid, Sociedad Española de Musicología/CSIC.

—. (2007) «Música para textos poéticos de la Edad de Oro: entre la tradición y la modernidad», dins Mariscal, B. (ed.) Actas del XV Congreso de la Sociedad Internacional de Hispanistas "Las dos orillas» (Monterrey, México, del 19 al 24 de julio de 2004), II, México, Fondo de Cultura Económica/ Asociación Internacional de Hispanistas/Tecnológico de Monterrey/El Colegio de México, pp. 641-656.

(2008) «Los resortes dramáticos del tono humano barroco», Teatro de Palabras. Revista sobre Teatro Aureo, 2, pp. 159-174 [publicación electrónica] <http://www.uqtr.ca/teatro/ teapal/ TeaPalNum02.html>.

- (2009) «Metamorfosis del tono humano barroco: variantes, pervivencias e implicaciones musicales en el teatro del siglo XvII», dins Álvarez Barrientos, J. \& Cornago Bernal, Ó. \& Madroñal Durán, A. \& Menéndez-Onrubia, C. (coords.) En buena compañia: estudios en honor de Luciano García Lorenzo, Madrid, CSIC, pp. 377-388. 
- (2012) «Góngora y la música», dins Roses, J. (ed.) Góngora, la estrella inextinguible: magnitud estética y universo contemporáneo. (Catálogo de la exposición en la Biblioteca Nacional de España, Madrid, del 30 de mayo al 19 de agosto de 2012. Sala Vimcorsa y Centro de Arte Pepe Espaliú, Córdoba, del 12 de septiembre al 11 de noviembre de 2012), Madrid, Sociedad Estatal de Acción Cultural, pp. 147-157.

——. (2013) Todo es amor. Manojuelo Poético-Musical de Barcelona (Biblioteca de Catalunya). Madrid, CSIC.

Hidalgo, J. (2017) Tonos y villancicos. Ed. de Josa, L. \& Lambea, M., Madrid, Dairea Ediciones.

Lambea, M. / Josa,L. (2016) Nuevoincipit depoesía española musicada (NIPEM), dins Digital CSIC: http:/ / hdl.handle.net/10261/44087. Disponible a: Biblioteca Virtual Miguel de Cervantes:http://bib. cervantesvirtual.com/portal/literaturaymusica/

Maravall, J. A. (1982) La cultura del Barroco, Barcelona, Ariel.

Rodríguez de la Flor, F. (1997) Biblioclasmo. Por una práctica crítica de la lecto-escritura, Valladolid, Junta de Castilla y León, Consejería de Educación y Cultura.

Rousset, J. (1972) Circe y el pavo real, Barcelona, Seix Barral.

Sarduy, S. (1969) Escrito sobre un cuerpo, Buenos Aires, Sudamericana.

Steiner, G. (1990) Lenguaje y silencio, Barcelona, Gedisa.

Valcárcel Rivera, C. (1993) «La realización y transmisión musical de la poesía en el Renacimiento español», tesis inédita, Universidad Autónoma de Madrid. 